\title{
Design on Full-Hydraulic Drive System of Corn Combine Harvester
}

\author{
Xie Fuxiang \\ School of Mechanical-electronic and Vehicle Engineering \\ Weifang University \\ Weifang, P.R.China \\ e-mail: xfx608@126.com
}

\begin{abstract}
In order to study the corn combine harvester hydraulic drive system, the hydraulic system was designed, which mainly consists of two valve blocks, eight branch circuits and other components, mainly for cutting device, snapping roll device, raking and conveying device, Transverse transport device, husker device and straw stacking device. And select the appropriate pump the hydraulic system, through the design shows that the system can complete functions, such as cutting, snapping roll, raking and conveying, Transverse transport, husker and straw stacking. One-way throttle valve was selected for MK10G1.2 / 2, Manual valve was chosen for 4WMM10J / F, and double vane pump was chosen for PFED-5141150/085. These circuits were connected in parallel among all systems, and the return line directly back to the tank. Provides the trial basis for the corn combine harvester machine.
\end{abstract}

Keywords- Corn; harvester ;hydraulic; system; design;

\section{INTRODUCTION}

Corn is one of the three major food crops in China, perennial planting area is maintained at more than 24 million $\mathrm{hm}^{2}$, the annual output of more than 12,000 million ton. Compared with wheat harvester level closed $87.8 \%$ and Rice $60 \%$,corn machine level is only $33 \%$. In order to break through 'bottlenecks' of the corn harvest mechanization and to promote the development of the corn industry, The urgent need for technological innovation ${ }^{[1]}$.

Hydraulic system in sugarcane combine harvester used widely ${ }^{[2 \sim 6]}$, and corn harvester in its infancy and compared with the world advanced level ${ }^{[7 \sim 8]}$, there is a large gap. Corn harvester can not be achieved by full hydraulic drive in a short time. The reliability of the hydraulic system on the corn harvest machinery applications is a big gap compared with the world's advanced level. Therefore, in order to improve the performance and stability of the hydraulic system, hydraulic system of corn combine harvester was designed in the paper, and to provide the technical basis for the development of the prototype.

\section{HYDRAULIC SYSTEM PRINCIPLE}

Corn combine harvester was mainly consisted of two valve blocks, eight branch circuits and other components, mainly for cutting device, snapping roll device, raking and conveying device, Transverse transport device, husker device and straw stacking device. As the hydraulic system actuator has more components, total was eight branch circuit (including two spare circuits), and therefore, taking into account the selection of the hydraulic pump. The hydraulic system in this paper wais designed, which consists of two main valve blocks, the valve blocks 1 to provide power for cutting device, snapping roll device, raking and conveying device from the double vane pump behind the pump oil. Transverse transport device. valve block 2 to provide power for husker device and straw stacking device from the double vane pump before the pump oil.

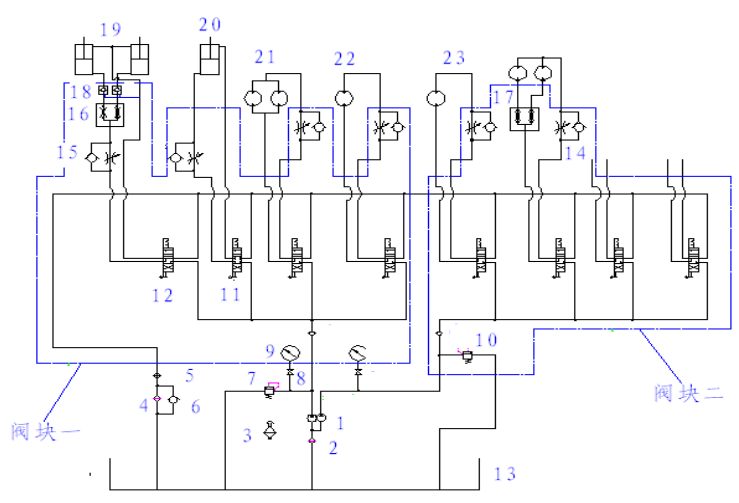

Figure 1.Hydraulic system principle

1Pair of vane pump 2,4 Air filter 5 Cooler 6 Unidirectional valve 7,10 Overflow valve 8 Pressure gauge switch 9 Pressure gauge 11, 12 Manual valve 13 Tank 14, 15 One-way throttle 16,17 shunt flow valve 18 Pilot unidirectional valve19, 20 Hydraulic cylinder 21, 22 motor

The total hydraulic system was shown in Fig .1. Operating principle of valve block was hydraulic oil flows through the unidirectional valve 6.2 , and then assigned to the four branch pipe fittings (for each branch in the oil flow and pressure, conditioned by the various branches of the one-way throttle). Since beginning work bench needs rise, and adjust the height of the position, the valve 12.1 was turned on, the oil into the hydraulic cylinder lifting entrance and directly back to the tank return. When snapping roll device was working, valve 12.1 was turned to the lower, and finished to adjust the position of the valve. When needs to be fixed, the valve transferred back in place. And adjusting the height position of the snapping roll device, the upper of valve 11 was turned on, and when 
dropped, the lower of valve 11 was turned on. Stationary, the valve 11 transferred back to the middle, to achieve self-locking, and directly back to the oil tank. When the raking and conveying device was working, lower of valve 12.2 was turned on, the one-way throttle valve in the oil was used to adjust the motor speed. Stopped working, the valve was back to middle. When transverse transport device was working, lower of valve 12.3 was turned on, one-way throttle valve in the oil was used to adjust the motor speed, and stopped working, valve transferred back to the position, directly back to the tank return.

Principle of valve block 2 was that hydraulic oil flows through the unidirectional valve 6.3 , and then assigned to the four branch pipe. The design was set in a husker device when the motor is working, lower of valve 12.4 was turned on, the one-way throttle valve in the oil was used to adjust the motor speed, directly back to the tank return. When Stopped working, the valve was transferred back to the median. There was straw stacking device, and need to be synchronized to run, then add a shunt flow valve on the return oil, the two motors for the oil to the same as flow. In working, lower of valve 12.5 was turned on, the one-way throttle valve in the oil was used to adjust the motor speed, directly back to the tank return. When Stopped working, the valve was transferred back to the median. Valve block 2 also set up two alternate circuit for the function of the system expansion.

\section{HYDRAULIC SYSTEM DESIGN}

\section{A. Design of the hydraulic circuit}

Hydraulic valve was hydraulic system control components, hydraulic system was used to controlling the flow direction, hydraulic pressure and flow, which the implementation of components and driven work machine to obtain the desired direction of movement, thrust (torque) and velocity (speed), etc., to meet the requirements of different actions. A working process and the quality of the hydraulic system, largely depends on various hydraulic valves used therein.

1) Hydraulic circuit of cutting device

The two bodies hydraulic cylinders on lifting of cutting device was designed in the circuit, and worked to be ensure synchronization that while lifting. If not ensure synchronous operation, which lead to the result in failure of the hydraulic cylinder. Therefore, the use of the shunt valve assembly to ensure that the two hydraulic cylinders to get the same flow rate, and to obtain the same amount of displacement. Also asked the bench was locked in any position, respectively, set the one-way valve in the oil back and into. Three-way valve was selected the manual valve, which functions was the Y-position and set up a one-way throttle into the oil, which control the rate of increase for the console shelf. One-way throttle valve selection SRC type, which type is SRCT-12. The SRC is expressing the one-way throttle, $\mathrm{T}$ indicates that the connection in the form of pipe connection , 03 is the path Code $10 \mathrm{~mm}$. The hydraulic circuit was shown in Fig .2.

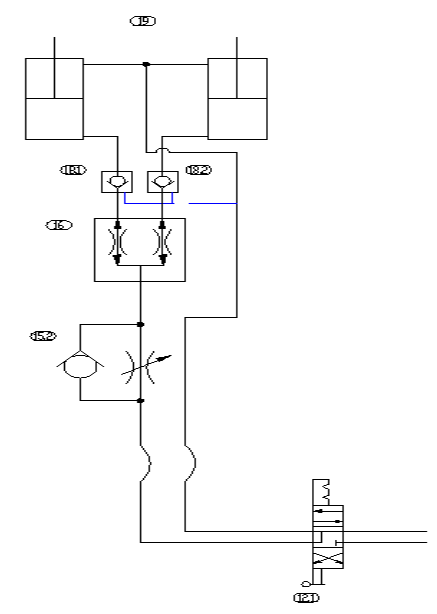

Figure 2.Hydraulic circuit on lifting mechanism of cutting device

2) Hydraulic circuit of snapping roll device

Hydraulic cylinder was only designed in elevating hydraulic circuit of snapping roll device, which circuit is relatively simple. A one-way throttle was set up for speed regulation of hydraulic cylinders extend.Hydraulic circuit of snapping roll device was shown in Fig .3. (II)

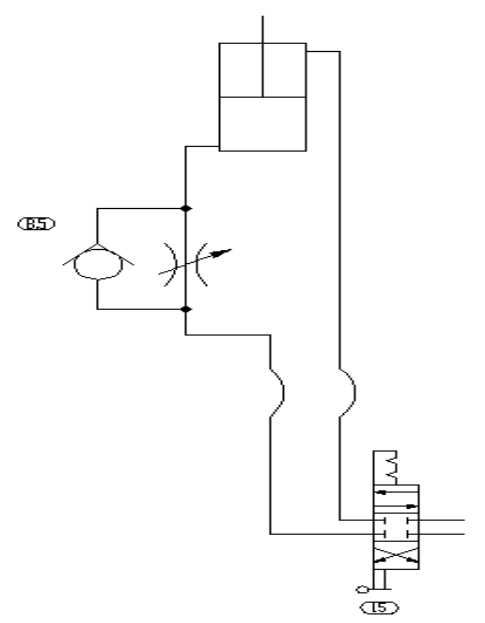

Figure 3. Lifting hydraulic cylinder circuit of snapping roll device

One-way throttle valve type was selected on the same valve with SRC. Manual valve was chosen for WMM type, the model for the 4WMM10E / F. And the above difference is that the choice of valve median function is $\mathrm{O}$ type, so it can be locked in any position for hydraulic circuit of snapping roll device.

3) Hydraulic circuit of raking and conveying device

The circuit set up two motors, symmetrical and there was no strictly synchronization requirements, so the application of a simple series circuit will be satisfied to the work requirements. Therefore, the two motors in series was designed, and one-way throttle was set up in the back to the oil, while the motor is used to adjust the speed of the hydraulic oil, and also serve to prevent reflux. The circuit also choose WMM type manual valve, valve model is $4 \mathrm{WMM} 10 \mathrm{~J} / \mathrm{F}$. As known to work when the motor is $13.9 \mathrm{~L} \cdot \min -1$, MK-type was one-way throttle valve, the model for MK10G1.2 / 2, which MK represents one-way throttle, 10 was diameter of $10 \mathrm{~mm}$, $\mathrm{G}$ represents 
pipe connection, 1.2 was the serial number and 2 was Metric. The hydraulic circuit system was shown in Fig .4.

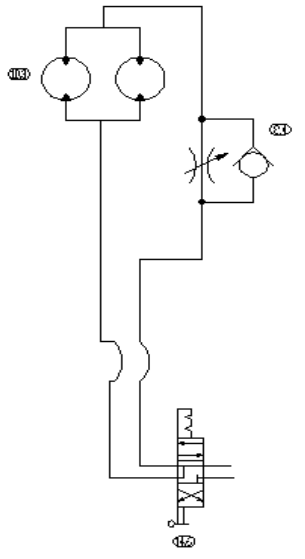

Figure 4. Hydraulic circuit of raking and conveying device

4)Hydraulic circuit of Transverse transport device

Hydraulic circuit of Transverse transport device was only one hydraulic motor, and relatively simple loop system, and a one-way throttle was set up in back to the oil. Because of the known motor during normal operation of the maximum flow was $21 \mathrm{~L} \cdot \mathrm{min}^{-1}$, one-way throttle valve was selected for MK-type, the model for MK10G1.2 / 2, consistent with the above liquid-way throttle valve motor drive circuit models. Manual valve was chosen for WMM type, the model for 4WMM10J / F, hydraulic circuit of Transverse transport device was shown in Fig .5.

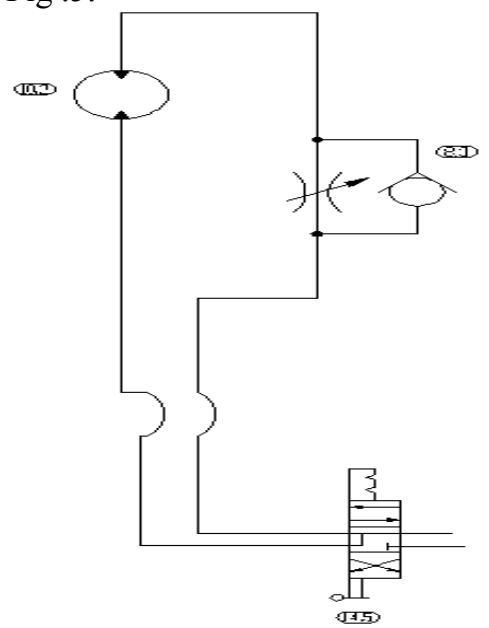

Figure 5.Hydraulic circuit of Transverse transport device

5) Hydraulic circuit of husker device

Hydraulic circuit of husker device was only one hydraulic motor, and relatively simple loop system, and a one-way throttle was set up in back to the oil. Because of the known motor during normal operation of the maximum flow was $43.5 \mathrm{~L} \cdot \mathrm{min}^{-1}$, one-way throttle valve was selected for MK-type, the model for MK10G1.2 / 2, consistent with the above liquid-way throttle valve motor drive circuit models. Manual valve was chosen for WMM type, the model for 4WMM10J / F, hydraulic circuit of husker device was shown in Fig 6.

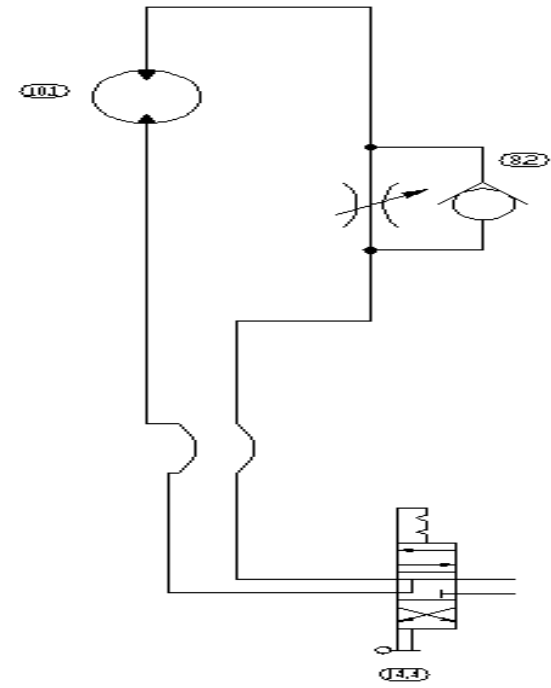

Figure 6. Hydraulic circuit of husker device

6) Hydraulic circuit of straw stacking device

Straw stacking device was set up two synchronized hydraulic motor in hydraulic circuit, in order to ensure accurate synchronization of two motor moving. A shunt valve assembly e was set up in the oil flow, while in the return line to set one-way throttle valve, so that both adjusting speed and also prevent backflow. Hydraulic circuit of straw stacking device was shown in Fig .7.

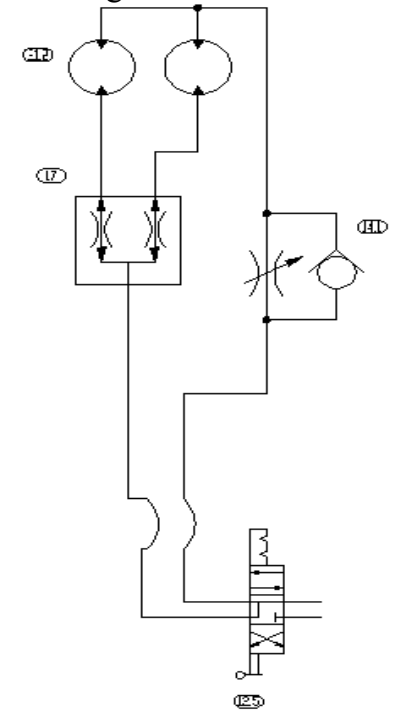

Figure 7. Hydraulic circuit of straw stacking device

All the circuits mentioned above, including cutting device, snapping roll device, raking and conveying device, and transverse transport device in the valve block 1, and husker device, straw stacking device and two alternate circuits in the valve block 2 . These circuits were connected in parallel among all systems, and the return line directly back to the tank. The hydraulic system has a total of three one-way valves, valve blocks each of two distributors to set up a one-way valve to prevent backflow of oil, the total return line was set up a one-way valve, in parallel with the return filter, play a role in protecting the oil filter. 


\section{B. Selection of pump}

Pump was powered for the entire hydraulic system components, which can be mechanical energy into pressure energy system, and passed to the system through the medium of the individual actuators. Quantitative hydraulic pump and variable displacement pump was divided, and also be divided into gear pumps, vane pumps, piston pumps and screw pump ${ }^{[9 \sim 10]}$.

This design was corn combine harvester hydraulic drive system, which type of host devices for mobile machinery. Due to work demands, hydraulic oil flow was larger, and does not require a pump to control the system pressure, and selected quantitative hydraulic pump and quantitative pump price is relatively cheap. The hydraulic system was consists of two separate valve block, and need to supply the initial choice of double vane pump.

1) The maximum working pressure of the hydraulic pump

The maximum working pressure of the hydraulic pump $\mathrm{P}_{\mathrm{P}}$ is $P_{P} \geq P_{1}+\Sigma \Delta P$

$\mathrm{P}_{1}$ was the maximum working pressure on implementation of the components in the loop, $\mathrm{P}_{1}$ is $12.2 \mathrm{MPa} ; \Sigma \triangle \mathrm{P}$ is pressure loss of the total road system into the oil, the experience of taking $\Sigma \triangle \mathrm{P}$ is $1 \mathrm{MPa}$, the pump's maximum working pressure.

2) Maximum flow pump

System for multiple actuators simultaneously, the maximum flow rate of the hydraulic pump should be greater than the total flow actuator action required at the same time, and should consider the leakage system.

$$
q_{P} \geq K(\Sigma q)_{\max }
$$

$\mathrm{K}$ is the leakage coefficient system, generally take $\mathrm{K}$ is 1.1 1.3(large flow take a small value, low flow whichever is greater), valve block 1 take $\mathrm{K}_{1}=1.3$, valve block 2 take $\mathrm{K}_{2}=1.1$, for simultaneous operation the maximum flow rate of the hydraulic actuator, the valve block 1 is $(\Sigma q)_{\max } \geq 70.9 \mathrm{~L} \cdot \mathrm{min}^{-1}$, block 2 is $(\Sigma q)_{\max } \geq 130.5 \mathrm{~L} \cdot \mathrm{min}^{-1}$.The minimum parameter each of valve block and overflow valve is $2 \mathrm{~L} \cdot \mathrm{min}^{-1}$, due to valve block 1 has two alternate circuits. Assuming that the total flow of two loops is $20 \mathrm{~L} \cdot \mathrm{min}^{-1}$, states of the valves block 1 is $q_{P 1} \geq 1.3 \times(70.9+2)=94.8 \mathrm{~L} \cdot \mathrm{min}^{-1}$, the valve block 2 is $q_{P 2} \geq 1.1 \times(130.5+2+20)=167.8 \mathrm{~L} \cdot \mathrm{min}^{-1}$.

3) Size selection of hydraulic pump

As the hydraulic system during operation may appear instantaneous pressure, so the system have a certain amount of pressure on reserve, so as not to cause damage to the system. Hydraulic pump rated flow and outlet flow $\mathrm{q}_{\mathrm{p}}$ is equal, otherwise should not exceed too much. $\mathrm{V}$ was calculated by the displacement of the pump.

$$
V=\frac{q_{p}}{n}
$$

$\mathrm{V}$ is the displacement, $\mathrm{cm}^{3} / \mathrm{r}, \mathrm{n}$ is the rotational speed, $\mathrm{r} / \mathrm{min}$, which should be close to the product of the rated speed. The hydraulic pump driven by a prime mover, $\mathrm{n}$ is $1500 \mathrm{r} / \mathrm{min}$. PFE double vane pump was chosen by comprehensive system, the internal structure of this pump is rather special, leaves stud structure and eccentric arrangement, this structure can not only pump output greater pressure and flow, smaller, and the efficiency is relatively high. Models was chosen for PFED$5141150 / 085$.

\section{CONCLUSION}

Determined to design the corn combine harvester hydraulic drive system, design of the hydraulic circuit and selection of pump.

In order to achieve low cost, high reliability, etc., corn combine harvester was designed, which mainly consisted of two valve blocks, eight branch circuits and other components, mainly for cutting device, snapping roll device, raking and conveying device, Transverse transport device, husker device and straw stacking device.

The design results show that the system can complete functions, such as cutting, snapping roll, raking and conveying, Transverse transport, husker and straw stacking.

\section{ACKNOWLEDGMENT}

The author wishes to express his sincere thanks to colleagues from the School of Mechanical-electronic and Vehicle Engineering Weifang University, and sponsor from the Science and Technology Development Project of Weifang(201301046) and The project on Doctoral Scientific Research Foundation funded of Weifang University (2013BS07) .

\section{REFERENCES}

[1] Chen Zhi,Hao Fuping,Wang Fengde.et.al.Development of technology and equipment of corn harvester in China[J]. Transactions of the Chinese Society for Agricultural Machinery,2012,43(12):44 50.

[2] Ou Y G, Wegener M, Yang D T. et al. Mechanization technology: The key to sugarcane production in China [J]. Int $\mathrm{J}$ Agric \& BiolEng,2013,6(1):1 27.

[3] He Zhi,Liu Qingting,Ou Yinggang.Dynamic response characteristic simulation of double-action variable displacement plunger pump for sugarcane harvester[J]. Transactions of the Chinese Society for Agricultural Machinery,2012,43(s1):329 334.

[4] Wang Haifei,Zhou Zhonghua,Zhang Chuanling.Modeling and simulation of sugarcane harvester hydraulic system based on amesim[J].Journal of ChongQing JiaoTong Univesity(Natural Science),2013,32(5):1063 1067.

[5] Chen Yuanling,Zhou Qidi,Huang Yunming.et.al.Simulation of the hydraumatic lifting system controlled by pressure feedback in sugarcane harvester's bench[J]. Journal of Agricultural Mechanization Research,2010(9):37 40.

[6] Wang Mingyou,Xiao Hongru,Li Xianwang.et.al.Application and research of hydraulic technology in the whole stalk sugarcane harvester[J].Chinese Agricultural Mechanization,2011,(4):83 85.

[7] Zhang Chengbao, LIU Xuefeng. Design and Research on the Hydraulic System of Model 4YZQ4 Self- propelled Corn Combine[J].Agricultural Equipment\&Vehicle Engineering. 2007(6): 19 21.

[8] He Huichao.Research on the Hydro-mechanical continuously variable transmission used in maize combine harvester[D].JiLin University,Changchun,2013.5

[9] Mechanical design manual editorial board. Mechanical design manual(Fifth Edition) [M]. Mechanical Industry Press, 2004,9

[10] Pu Lianggui. Mechanical design(Eighth Edition) [M]. Higher education press, 2010,5 